\title{
Endotracheal Tube Seal and Suction Performance in a Novel Biorealistic Tracheal Model
}

\author{
Sarah K Rozycki, Fredrick P Dixon, Melissa A Yopp MSHA, Norma J Maxvold MD, and \\ Bruce K Rubin MEngr MBA MD FAARC
}

\begin{abstract}
BACKGROUND: Endotracheal tube (ETT) cuffs create a seal to protect against secretion entry to the lungs. Cuff inflation currently is recommended at $20-30 \mathrm{~cm} \mathrm{H}_{2} \mathrm{O}$ pressure. ETT designs have variable seal performance in bench studies using rigid tracheal models lacking the dynamic characteristics of the human trachea. We compared ETT designs within a new, biorealistic tracheal model to assess cuff and suction performance in the setting of a compliant trachea. METHODS: Three ETT designs (Mallinckrodt Hi-Lo, KimVent Microcuff, and Sheridan/HVT) were tested for performance by simulant leakage below the cuff and air leakage (measured as return tidal volume $\geq 80 \%$ delivered) over a range of cuff $\left(5-25 \mathrm{~cm} \mathrm{H}_{2} \mathrm{O}\right)$ and end-expiratory pressure (PEEP 0-15 cm $\mathrm{H}_{2} \mathrm{O}$ ). Subglottic suction channel performance was tested in 2 ETTs (TaperGuard Evac [Covidien] and ISIS HVT [Teleflex]) as time to evacuate the simulant. RESULTS: All ETT cuffs provided effective seals at an inflation pressure of $12 \mathrm{~cm} \mathrm{H}_{2} \mathrm{O}$ when PEEP was $\leq 5 \mathrm{~cm} \mathrm{H}_{2} \mathrm{O}$. The Microcuff ETT sealed at the lowest pressure of $6 \mathrm{~cm} \mathrm{H}_{2} \mathrm{O}$, whereas the Sheridan/HVT cuff sealed at $12 \mathrm{~cm} \mathrm{H}_{2} \mathrm{O}(P=.01)$. With a PEEP of $15 \mathrm{~cm} \mathrm{H}_{2} \mathrm{O}$, a reciprocal increase in air leak occurred, requiring a cuff inflation up to $22 \mathrm{~cm} \mathrm{H}_{2} \mathrm{O}$ to maintain a return tidal volume at $\geq 80 \%$ delivered. Suction channel performance improved in the lateral position compared with supine for both ETT designs during continuous $15 \mathrm{~mm} \mathrm{Hg}$ suction pressure $(P=.001)$. CONCLUSIONS: Within a novel model with normal trachea compliance, we found all ETT designs tested to seal at lower than current recommended cuff pressures. Key words: mucus; suctioning; endotracheal tube; ventilatorassociated pneumonia; insufflation pressure; compliance. [Respir Care 2015;60(8):1113-1119. (C) 2015 Daedalus Enterprises]
\end{abstract}

\section{Introduction}

Ventilator-associated pneumonia has often been attributed to secretion leak around the endotracheal tube (ETT)

\footnotetext{
Ms Rozycki, Ms Yopp, and Drs Maxvold and Rubin are affiliated with the Department of Pediatrics, Virginia Commonwealth University School of Medicine and the Children's Hospital of Richmond at Virginia Commonwealth University, Richmond, Virginia. Mr Dixon is affiliated with Teleflex Medical, Research Triangle Park, North Carolina.
}

Ms Rozycki presented a version of this paper at the American Association for Respiratory Care Congress, held November 16-19, 2013, in Anaheim, California.

This study was supported by a research grant from Teleflex Medical, Research Triangle Park, North Carolina. Ms Rozycki received travel expense support for the abstract presentation at the American Association for Respiratory Care Congress from Teleflex Medical. Mr Dixon is employed by Teleflex Medical. Dr Rubin's laboratory received research cuff. Costs of ventilator-associated pneumonia are estimated to average 9 extra hospital days and greater than $\$ 40,000$ additional expense per patient. ${ }^{1,2}$ Bundles of care that reduce the risk of ventilator-associated pneumonia include oral hygiene, semi-recumbent positioning, and suctioning techniques. Modifications of ETT cuff geometry, materials, and suction channels can further reduce risk of ventilator-associated pneumonia. ${ }^{3-5}$ Pliability and thickness of the cuff materials have been found to affect cuff seal performance, as has shape and length of the cuff. ${ }^{6-10}$

\footnotetext{
funding for this study from Teleflex Medical. All other authors have disclosed no conflicts of interest.

Correspondence: Norma J Maxvold MD, Children's Hospital of Richmond, Virginia Commonwealth University, Box 980530, Richmond, VA 23298. E-mail: nmaxvold@mcvh-vcu.edu.
}

DOI: $10.4187 /$ respcare.03799 
Recommended cuff inflation pressures are $20-30 \mathrm{~cm}$ $\mathrm{H}_{2} \mathrm{O},{ }^{11,12}$ which is about equal to tracheal perfusion pressure reported to be $22 \mathrm{~mm} \mathrm{Hg}$ in a healthy trachea ${ }^{13}$ and may be lower with disease. Higher ETT cuff pressure may cause injury to the mucosa and lead to complications. ${ }^{13,14}$ Distribution of cuff pressure to the tracheal wall is heterogeneous, with regions of the tracheal wall receiving higher than the set internal cuff pressure. ${ }^{6}$

In vitro studies of ETT performance have typically used rigid trachea models. ${ }^{7-9,15}$ Although these allow for comparison between ETT designs, they do not represent the dynamic motion of the human trachea and its effect on ETT cuff performance. The airway motion is dynamic, leading to cross-sectional changes in response to airway pressures. ${ }^{16,17}$ A new biorealistic trachea model replicating the compliance of adult human tracheae has been developed. ${ }^{18}$ Our study's aim was to evaluate ETT performance within this trachea model, which mirrors intrinsic tracheal compliance. ETT cuff performance was assessed by measuring secretion leakage below the cuff and effective return tidal volume $\left(\mathrm{V}_{\mathrm{Te}}\right)$ over a range of cuff inflation pressures and airway pressures. Subglottic suction channel efficiency was also evaluated. The study was performed in the Department of Pediatrics, Virginia Commonwealth University School of Medicine (Richmond, Virginia).

\section{Methods}

\section{Biorealistic Tracheal Model}

A 2-piece model with dimensions, surface topography, and rheology matched to that of a normal adult human trachea was used for testing. The model consisted of a mouth-throat component ${ }^{19}$ and trachea through the bifurcation of the main stem bronchi that approximates the cross-section profiles reported for the adult human airway. ${ }^{20}$ The trachea component was scaled to match the cross-sectional area from images of the tracheal airway of adults ${ }^{16}$ and was prototyped using Tango Plus FullCure 930 (Objet Geometries, Billerica, Massachusetts), a viscoelastic material. ${ }^{18}$ Adjustments of cartilaginous ring thickness, esophageal interface thickness, esophageal interface width, and esophageal indention were made and tested to match reported non-linear in vivo data. ${ }^{18}$ The final dimensions of the tracheal model were $2 \mathrm{~mm}$ thickness for cartilaginous rings, $0.75 \mathrm{~mm}$ for esophageal interface thickness, $15 \mathrm{~mm}$ for esophageal interface width, and $2.15 \mathrm{~mm}$ for esophageal indention with a distance ratio between the anterior tracheal surface and the posterior esophageal crest to trough of 0.82 . Validation of compliance matching was performed by inserting a 7.0-mm ETT with a standard cuff to the mid-tracheal position and using pressures of $0-30 \mathrm{~cm} \mathrm{H}_{2} \mathrm{O}$ by incremental cuff in-

\section{QUICK LOOK}

\section{Current knowledge}

The endotracheal tube cuff allows positive pressure ventilation and protects the airway from aspiration. Standard cuff pressures of $20-30 \mathrm{~cm} \mathrm{H}_{2} \mathrm{O}$ are typically used to prevent leakage of fluid around the cuff and to prevent mucosal injury. In recent years, laboratory evaluations of cuffs in glass models have demonstrated reduced fluid leakage, but clinical studies have not confirmed these findings in vitro.

\section{What this paper contributes to our knowledge}

In a realistic viscoelastic model of the trachea, endotracheal tube cuffs of different designs provided an adequate seal at a pressure of $12 \mathrm{~cm} \mathrm{H}_{2} \mathrm{O}$. With increased PEEP, higher cuff pressures were required. Tubes with a subglottic suction channel performed best in the lateral position.

flation of $5 \mathrm{~cm} \mathrm{H}_{2} \mathrm{O}$ pressure as measured by the Cufflator (Posey, Arcadia, California).

\section{Ventilator Circuit Set-Up}

The mouth-throat model was intubated with a $7.0 \mathrm{~mm}$ ETT and connected to a Nellcor Puritan Bennett 800 series ventilator (Covidien, Mansfield, Massachusetts) with $100 \%$ saturated air heated to $37 \pm 0.6^{\circ} \mathrm{C}$ (ConchaTherm Neptune heated humidifier, Teleflex, Research Triangle Park, North Carolina). The distal bifurcating end of the trachea model was connected to $2 \mathrm{~L}$ anesthesia bags fully inflated to $2 \mathrm{~L}$ volume to represent a low compliant lung (Fig. 1) and maintained for $1 \mathrm{~h}$ for equilibration of the heated, humid-

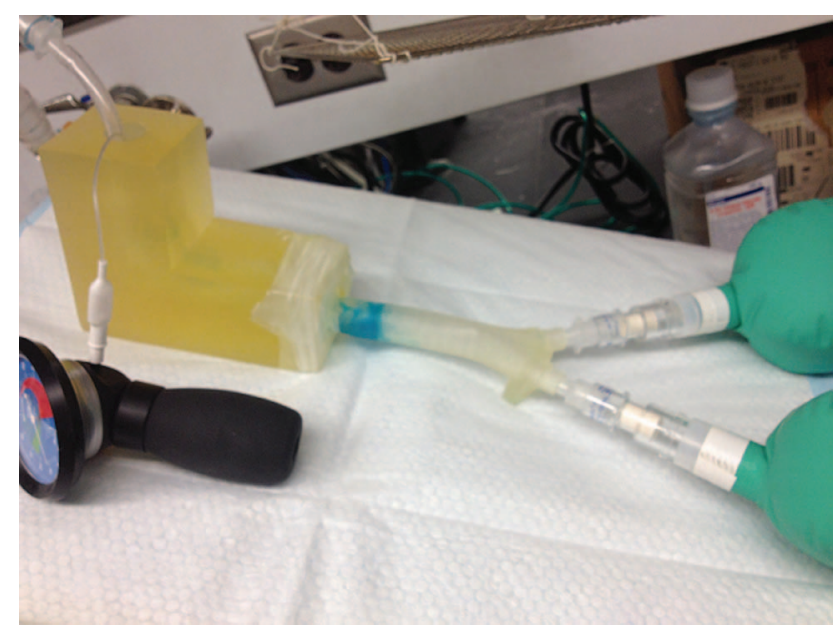

Fig. 1. Intubated compliant trachea model set-up. 
Table 1. Rheology of Mucus Simulant

\begin{tabular}{lcc}
\hline \hline & & Mucus Simulant Concentration \\
\cline { 2 - 3 } Viscoelasticity & $0.25 \%$ & $0.5 \%$ \\
\hline $\mathrm{G}^{\prime}$ at $1 \mathrm{rad} / \mathrm{s}$ & $4.73 \times 10^{-11} \pm 7.14 \times 10^{-11}$ & $6.14 \times 10^{-10} \pm 7.81 \times 10^{-10}$ \\
$\mathrm{G}^{\prime \prime}$ at $1 \mathrm{rad} / \mathrm{s}$ & $2.20 \times 10^{-4} \pm 4.57 \times 10^{-5}$ & $1.24 \times 10^{-3} \pm 1.85 \times 10^{-4}$ \\
$\mathrm{G}^{\prime}$ at $100 \mathrm{rad} / \mathrm{s}$ & $3.07 \times 10^{-3} \pm 4.04 \times 10^{-3}$ & $0.026 \pm 0.017$ \\
$\mathrm{G}^{\prime \prime}$ at $100 \mathrm{rad} / \mathrm{s}$ & $2.15 \pm 0.281$ & $12.1 \pm 1.53$
\end{tabular}

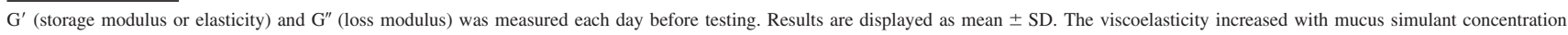

ified circuit before beginning the ETT cuff performance assessments. Ventilator settings selected for testing consisted of a flow of $40 \mathrm{~L} / \mathrm{min}$, tidal volume $\left(\mathrm{V}_{\mathrm{T}}\right) 500 \mathrm{~mL}$, inspiratory time $1.0 \mathrm{~s}$, and frequency 12 cycles/min. The ventilated mouth-throat model was elevated to $30^{\circ}$ above the horizontal plane to reflect the practice of semi-recumbent positioning of intubated patients.

\section{Mucus Simulant}

Polyox water-soluble resin N-750 solution (Dow Chemicals, Woodbury, New Jersey) was used as the simulant for leak detection at a $0.25 \%$ concentration. A $0.5 \%$ Polyox solution, found previously to display characteristics similar to salivary secretions, was used in suction testing. ${ }^{21}$ The $0.25 \%$ simulant was made by heating $200 \mathrm{~mL}$ of deionized water to $95-97^{\circ} \mathrm{C}$ and adding $0.5 \mathrm{~g}$ of Polyox. The solution was removed from heat and mixed for $1-2 \mathrm{~h}$ until homogenous. Simulant secretions were dyed blue for visualization purposes. The rheology of the simulant (Table 1) was measured each day to ensure consistency throughout testing.

\section{ETT Performance}

Cuff performance of $37.0 \mathrm{~mm}$ internal diameter ETT designs (KimVent Microcuff, Kimberly-Clark, Roswell, Georgia; Mallinckrodt Hi-Lo, Covidien; and Sheridan/HVT, Teleflex) were evaluated within the trachea-ventilator circuit. These ETT designs displayed cuff material and geometry differences: polyurethane and cylindrical, polyvinylchloride and cylindrical, and polyvinylchloride and tapered, respectively. Testing occurred over cuff pressure of 5-25 $\mathrm{cm} \mathrm{H}_{2} \mathrm{O}$ and PEEP of $0-15 \mathrm{~cm} \mathrm{H}_{2} \mathrm{O}$ (Table 2). Triplicate testing of each ETT design was assessed for a period of 20 min under each test condition, with manometer (EndoTest; Rusch, Research Triangle Park, North Carolina) monitoring of cuff insufflation pressures. Five $\mathrm{mL}$ of simulant was added into the mouth of the model when testing 3 ETTs of each design for cuff seal performance, as measured by percentage of simulant leak past the cuff and $\mathrm{V}_{\mathrm{Te}}$.
Table 2. PEEP and Cuff/ $/ \mathrm{V}_{\mathrm{Te}}$ Test Conditions

\begin{tabular}{lc}
\hline \hline $\begin{array}{c}\text { PEEP } \\
\left(\mathrm{cm} \mathrm{H}_{2} \mathrm{O}\right)\end{array}$ & $\begin{array}{c}\text { Cuff Pressure } \\
\left(\mathrm{cm} \mathrm{H}_{2} \mathrm{O}\right)\end{array}$ \\
\hline 0 & 5 \\
0 & 10 \\
0 & 15 \\
0 & 25 \\
5 & 15 \\
5 & 25 \\
5 & $*$ \\
15 & 25 \\
15 & $*$ \\
*Lowest cuff pressure to sustain return tidal volume $\left(\mathrm{V}_{\mathrm{Te}}\right) \geq 400 \mathrm{~mL}$. & \\
\hline
\end{tabular}

Two Humid-Vent Mini-filters (Teleflex) were placed at the bifurcation before the connection to the anesthesia bags to capture the colored simulant. The filters were removed after each test and submerged in $40 \mathrm{~mL}$ of saline. After $2 \mathrm{~h}$ of diffusion, the $40 \mathrm{~mL}$ saline-simulant solution was measured by an absorbance microplate reader (Biotek, Winooski, Vermont) to determine optical density. Leak percentage was determined by comparing the optical density of the sample with an optical density curve of known volumes of simulant diluted to $40 \mathrm{~mL}$ of saline. Test conditions with no visible cuff leak and a leak percentage less than $1 \%$ were considered to have zero cuff leakage.

\section{ETT Subglottic Suction}

ETTs with suction capability (TaperGuard Evac and ISIS HVT) were evaluated at 15 and $20 \mathrm{~mm} \mathrm{Hg}$ continuous pressure and at 100 and $120 \mathrm{~mm} \mathrm{Hg}$ intermittent suction pressure, using the bench ventilator-trachea circuit with constant cuff pressure and PEEP of 25 and $5 \mathrm{~cm} \mathrm{H}_{2} \mathrm{O}$, respectively. The ETT suction port was attached to a suction trap connected to a pressure regulator (Boehringer, Phoenixville, Pennsylvania). Suction efficiency was assessed as time required to aspirate $7 \mathrm{~mL}$ of $0.5 \%$ Polyox simulant and was tested in triplicate for each ETT design 


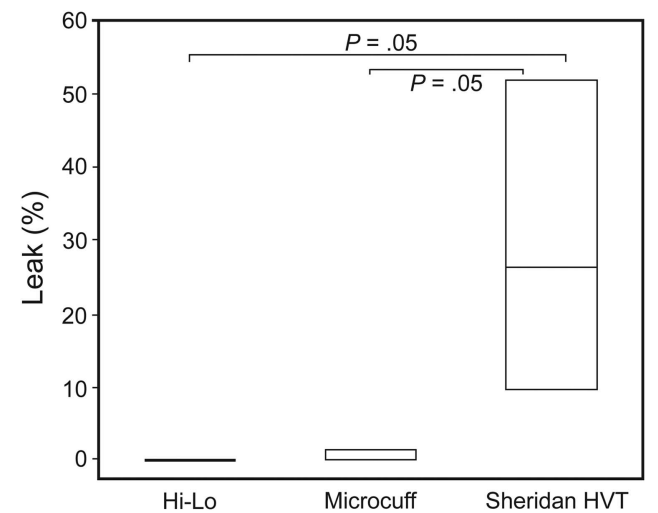

Fig. 2. Simulant leak percentage at PEEP of $0 \mathrm{~cm} \mathrm{H}_{2} \mathrm{O}$, endotracheal tube cuff pressure of $5 \mathrm{~cm} \mathrm{H}_{2} \mathrm{O}$. Box denotes full range of 3 data points.

in both supine and lateral position. If mucus simulant was not completely cleared by $4 \mathrm{~min}$, the test was stopped and deemed incomplete clearance. Occlusion of the suction channel was assessed visually by inward deviation of the posterior tracheal wall during suctioning, graded as complete (total obstruction with cessation of suctioning) or mild (disturbance of the posterior wall without impact on suction clearance).

\section{Statistical Analysis}

Data analysis was performed using the JMP Pro 10 statistics package (SAS Institute, Cary, North Carolina). Cuff seal and suction efficiency were analyzed by oneway analysis of variance and post hoc Tukey test. By convention, $P<.05$ was considered significant. A separate analysis of variance under each test condition was done to diminish heterogeneity caused by mixing results over all test conditions. We have displayed the results as box plots to show the range of data. Because the assessment of membrane occlusion was observational, no statistical test was applied.

This study was a laboratory investigation and employed no animal or subject participation, and therefore was exempt from the need for institutional review board approval.

\section{Results}

\section{Simulant Leak Below the ETT Cuff}

All ETT designs performed well with no simulant leak at cuff pressures of 10,15 , and $25 \mathrm{~cm} \mathrm{H}_{2} \mathrm{O}$, regardless of PEEP. Simulant leakage occurred only when no PEEP was present and at the low cuff pressure of $5 \mathrm{~cm} \mathrm{H}_{2} \mathrm{O}$. A significant difference in leak percentage was observed between the Sheridan/HVT and both Microcuff and Mallinck-

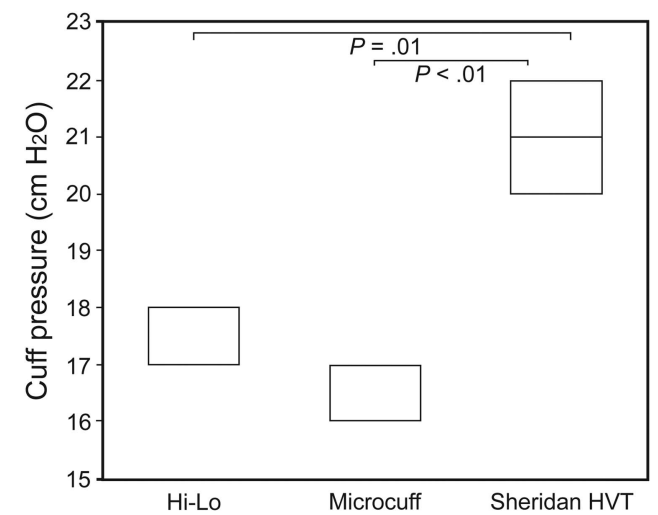

Fig. 3. Lowest endotracheal tube cuff pressure to maintain return tidal volume $\left(\mathrm{V}_{\mathrm{Te}}\right) \geq 400 \mathrm{~mL}$ at PEEP of $15 \mathrm{~cm} \mathrm{H}_{2} \mathrm{O}$. Box denotes full range of 3 data points.

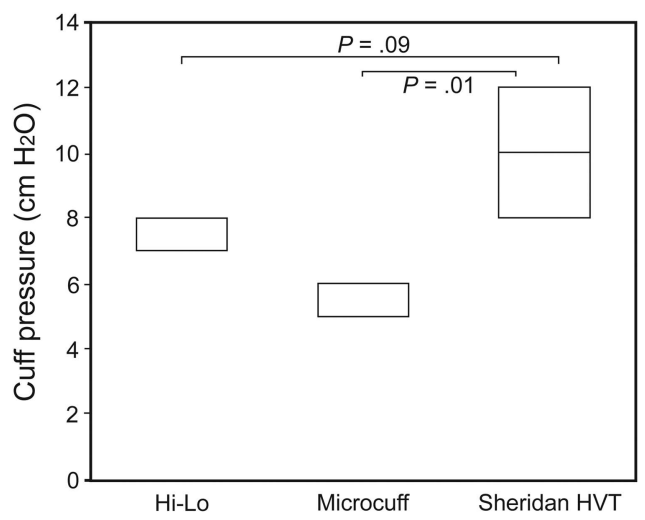

Fig. 4. Lowest endotracheal tube cuff pressure to maintain return tidal volume $\left(\mathrm{V}_{\mathrm{Te}}\right) \geq 400 \mathrm{~mL}$ at PEEP $5 \mathrm{~cm} \mathrm{H} \mathrm{H}_{2} \mathrm{O}$. Box denotes full range of 3 data points.

rodt Hi-Lo $(P=.05)$, with a range of $0-29.3 \pm 21.2 \%$ (Fig. 2).

\section{Return Tidal Volume}

Increasing PEEP decreased the $\mathrm{V}_{\mathrm{Te}}$ in all tested ETTs. The lowest cuff pressure that maintained a $\mathrm{V}_{\mathrm{Te}}$ of $400 \mathrm{~mL}$ ( $>80 \%$ delivered, common clinical practice to minimize reinstrumentation by the vocal cords and yet be accommodated through leak compensation mechanics on current ventilators) varied with ETT design. When PEEP was $15 \mathrm{~cm} \mathrm{H}_{2} \mathrm{O}$ (Fig. 3), the cuff pressure needed for the Microcuff ETT to maintain $\mathrm{V}_{\mathrm{Te}}>400 \mathrm{~mL}$ was $16 \pm 0.5 \mathrm{~cm} \mathrm{H}_{2} \mathrm{O}$, which is significantly less than the Sheridan/HVT cuff pressure of $21 \pm 1 \mathrm{~cm} \mathrm{H}_{2} \mathrm{O}(P<.01)$. During ventilation with PEEP of $5 \mathrm{~cm} \mathrm{H}_{2} \mathrm{O}$, all ETT designs maintained $\mathrm{V}_{\mathrm{Te}}>80 \%$ delivered at a cuff inflation pressure of $12 \mathrm{~cm} \mathrm{H}_{2} \mathrm{O}$ (Fig. 4). The Microcuff ETT sealed at the lowest insufflation pressure of $6 \mathrm{~cm} \mathrm{H}_{2} \mathrm{O}$, while the Sheridan/HVT cuff sealed at $12 \mathrm{~cm} \mathrm{H}_{2} \mathrm{O}(P=.01)$. 


\section{ETT Performance in a Biorealistic Tracheal Model}
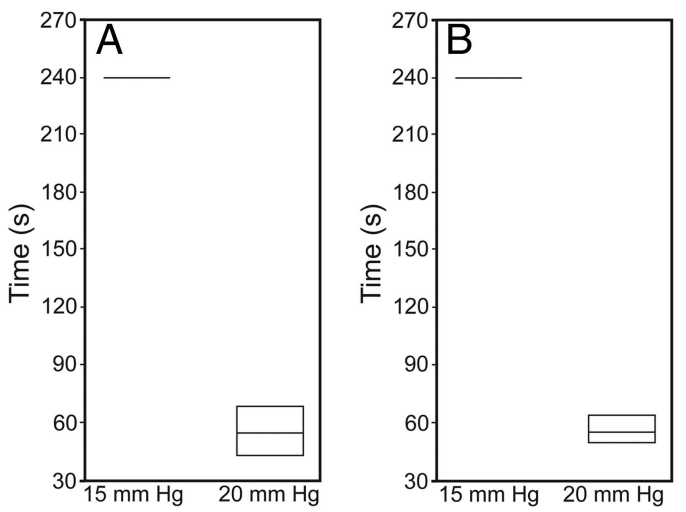

Fig. 5. Suction channel efficiency (time) for complete simulant removal, at $15 \mathrm{~mm} \mathrm{Hg}$ versus $20 \mathrm{~mm} \mathrm{Hg}$ continuous suction pressure using A: ISIS HVT and B: TaperGuard Evac. Boxes denote full range of 3 data points. $P<.01$ between 15 and $20 \mathrm{~mm} \mathrm{Hg}$ in both scenarios.
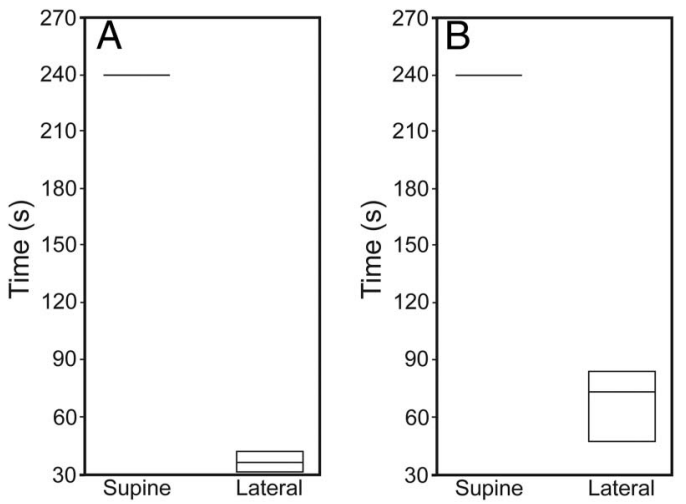

Fig. 6. Suction channel efficiency (time) for complete simulant removal in supine versus lateral trachea position, under $15 \mathrm{~mm} \mathrm{Hg}$ continuous suction pressure using A: ISIS HVT and B: TaperGuard Evac. Boxes denote full range of 3 data points. $P<.01$ between supine and lateral positions in both scenarios.

\section{Subglottic Suction Channel}

ETT suction channels cleared secretions in less than $3 \mathrm{~s}$ when using intermittent suction at pressures of 100 or $120 \mathrm{~mm} \mathrm{Hg}$ regardless of the trachea position, supine or lateral. Neither suction channel design performed well in the supine position with continuous suction pressure of $15 \mathrm{~mm} \mathrm{Hg}$, failing to completely evacuate $7 \mathrm{~mL}$ of simulant by $4 \mathrm{~min}$. However, at a slightly higher continuous suction pressure of $20 \mathrm{~mm} \mathrm{Hg}$, there was complete simulant clearance (Fig. 5). Rotating the trachea into a lateral position further improved the performance for both designs, with complete secretion clearance at the lowest suction pressure $(15 \mathrm{~mm} \mathrm{Hg}$ ) tested (Fig. 6). There was no tracheal membrane displacement using low, continuous suction pressures. There was displacement of the posterior tracheal wall in both ETT designs using high intermittent suction pressures regardless of model position, although complete obstruction did not occur.

\section{Discussion}

Our objectives were to evaluate cuff seal effectiveness and the performance of the subglottic suction channel of different ETT designs using a novel, biorealistic tracheal model. To our knowledge, this is the first bench study of ETT performance using an airway model that matches the dynamic properties of the trachea. Young et $\mathrm{al}^{22}$ performed a combined bench and in vivo study of ETT performance using excised pig tracheas of approximately the same diameter as an adult human; however, the tracheae used were up to 1 day old, at which point tracheal compliance was lost due to cellular calcium leak into the tissue, causing muscle to rigor. In their model, leakage occurred in $44 \%$ of the endotracheal tubes tested, at the cuff pressure of $30 \mathrm{~cm} \mathrm{H}_{2} \mathrm{O}$, which is more consistent with leakage found in rigid trachea models than found in our study, where simulant leakage did not occur at cuff inflation pressures $\geq 10 \mathrm{~cm} \mathrm{H}_{2} \mathrm{O}$.

A significant limitation of our study may have been the use of fully inflated anesthesia bags to represent a low compliant lung. This may in itself have exaggerated the air leakage around the inflated cuffs (as measured by $\mathrm{V}_{\mathrm{Te}}$ ) during testing. Nonetheless, within all ETTs tested, a cuff inflation pressure of $12 \mathrm{~cm} \mathrm{H}_{2} \mathrm{O}$ or greater prevented secretion leakage and maintained $\mathrm{V}_{\mathrm{Te}} \geq 80 \%$ delivered when PEEP was $5 \mathrm{~cm} \mathrm{H}_{2} \mathrm{O}$ or less. This is lower than published recommendations that cuff pressure be maintained at $20-30 \mathrm{~cm} \mathrm{H}_{2} \mathrm{O}^{12,23,24}$ It is likely that compliance of the trachea diminishes the effect of cuff folding on leakage, possibly through the posterior membranous portion conforming around the cuff. In studies using a rigid airway model, only one ETT design, Microcuff, prevented air or secretion leak around the cuff at a similar lower inflation pressure of $15 \mathrm{~cm} \mathrm{H}_{2} \mathrm{O} .7,8$ This rigid model was not heated or humidified. Studies have suggested that moisture improves cuff seal by partially filling folds and cuff channels. ${ }^{23,25}$ Our study employed a humidified, heated circuit within the compliant trachea model.

The ETTs used in our study were those readily available to our institution and represent different cuff designs (cylindrical or tapered) and materials (polyvinyl chloride or polyurethane). Studies have demonstrated that cuff geometry and material affects performance, with improved sealing noted in polyurethane or silicone cuffs and tapered shape. $6,8,9,22$ Although we found performance differences between ETT designs, all ETTs tested provided an effective seal at cuff pressures lower than reported in studies using rigid tracheal models. 
If compliance of the trachea plays a role in cuff sealing, then, at a higher airway pressure where there is decreased compliance, cuff sealing should be more difficult, requiring increased inflation to maintain effective seal. This has been demonstrated in vivo, ${ }^{26}$ and our study confirmed this effect of airway pressure on sealing. We found that, to maintain an effective $\mathrm{V}_{\mathrm{Te}}$ of $\geq 80 \%$ delivered at a PEEP of $15 \mathrm{~cm} \mathrm{H} \mathrm{H}_{2} \mathrm{O}$, an ETT cuff pressure up to $22 \mathrm{~cm} \mathrm{H}_{2} \mathrm{O}$ was needed, considerably higher than the cuff pressure needed at low PEEP.

Our study design differed from many of the reported bench studies in regards to trachea positioning. We aimed to replicate patient care in a semi-recumbent position. This position decreases the gravity effects on secretions above the cuff and represents usual patient care practice. A study comparing different ETTs for fluid sealing and transmitted tracheal wall pressure similarly used the semi-recumbent position. ${ }^{6}$ The authors found a heterogeneous pressure distribution to the tracheal wall and proposed that increased folding of cuffs with larger outer diameter may play a role in this uneven pressure distribution. This study used a rigid trachea model, however, so the effect of tracheal compliance on the distribution of ETT cuff pressure or sealing was not assessed.

We evaluated suction channel performance in the supine and lateral positions. Better secretion clearance was found in the lateral position under low, continuous $15 \mathrm{~mm} \mathrm{Hg}$ suction. Additionally, deviation of the posterior tracheal wall was observed at $\geq 100 \mathrm{~mm} \mathrm{Hg}$ suction pressure, but complete occlusion of the orifice was not observed. This is likely due to using less than $3 \mathrm{~s}$ of high suction to clear the secretions. In clinical practice, suctioning intervals can vary. Tracheal trauma has been described primarily with continuous subglottic suction..$^{27,28}$ Our finding of improved suction aspiration in the lateral position, allowing complete clearance of the secretions during continuous low $15 \mathrm{~mm} \mathrm{Hg}$ suction pressure, may have clinical importance. Many institutions use a rotary bed or frequent repositioning of critically ill, intubated patients for prevention of skin breakdown, replicating this lateral position intermittently. Studies evaluating subglottic suction aspiration have not evaluated positional effect on secretion clearance or whether rotation may decrease mucosal injury during continuous suction techniques.

Aspects of ETT performance we did not address in this initial study of the compliant trachea model include replicating our findings of cuff seal performance with multiple sizes of ETTs. Only one size of ETT was tested due to cost constraints. We also chose to observe for leakage over 20-min intervals; this may not be the optimal interval for assessment of ETT performance within a compliant tracheal model, and clearly does not represent a protracted intubated patient experience. Cuff pressures were continuously monitored and maintained, whereas, in clinical prac- tice, there is drift in cuff pressures over time. ${ }^{29}$ Movement or suctioning of ETTs with under-inflated cuffs has also resulted in higher rates of micro-aspiration. ${ }^{22,30} \mathrm{We}$ did not manipulate our trachea model by suctioning or movement during the study. Further testing with multiple sizes of ETTs and under the movement conditions similar to patient care within this new, biorealistic tracheal model are needed.

Statistical analysis in this pilot study of a new compliant trachea model is limited due to the small number of ETTs tested. Extended work within the compliant trachea model, replicating and expanding these preliminary findings of a lower cuff pressure providing adequate sealing properties that prevent secretion leakage is needed before considering a change from current recommended cuff inflation pressures.

\section{Conclusions}

Using a novel in vitro tracheal model with dynamic characteristics matching that of an adult human airway, we demonstrated that tracheal compliance has an effect on ETT cuff performance. We found lower cuff pressures than currently recommended provided an effective seal against secretion leakage when PEEP was $\leq 5 \mathrm{~cm} \mathrm{H}_{2} \mathrm{O}$ with a cuff threshold pressure of $12 \mathrm{~cm} \mathrm{H}_{2} \mathrm{O}$ for sealing. At higher airway pressures where tracheal compliance is diminished, higher cuff pressure was required to maintain effective $\mathrm{V}_{\mathrm{T}}$. We further found suction channel performance at low $(15 \mathrm{~mm} \mathrm{Hg})$ continuous suction pressure to improve with rotation to a lateral position. Additional studies to expand this appreciation of the innate tracheal compliance effect on cuff performance are needed.

\section{ACKNOWLEDGMENTS}

We thank Drs Walenga and Longest for the design and development of the compliant tracheal model we used in this study.

\section{REFERENCES}

1. Leistner R, Kankura L, Bloch A, Sohr D, Gastmeier P, Geffers C. Attributable costs of ventilator-associated lower respiratory tract infection (LRTI) acquired on intensive care units: a retrospectively matched cohort study. Antimicrob Resist Infect Control 2013; 2(1):13.

2. Rello J, Ollendorf DA, Oster G, Vera-Llonch M, Bellm L, Redman $\mathrm{R}$, et al. Epidemiology and outcomes of ventilator-associated pneumonia in a large US database. Chest 2002;122(6):2115-2121.

3. Lorente L, Blot S, Rello J. New issues and controversies in the prevention of ventilator-associated pneumonia. Am J Respir Crit Care Med 2010;182(7):870-876.

4. Berra L, Sampson J, Fumagalli J, Panigada M, Kolobow T. Alternative approaches to ventilator-associated pneumonia prevention. Minerva Anestesiol 2011;77(3):323-333. 
5. Efrati S, Deutsch I, Antonelli M, Hockey PM, Rozenblum R, Gurman GM. Ventilator-associated pneumonia: current status and future recommendations. J Clin Monit Comput 2010;24(2):161-168.

6. Li Bassi G, Ranzani OT, Marti JD, Giunta V, Luque N, Isetta V, et al. An in vitro study to assess determinant features associated with fluid sealing in the design of endotracheal tube cuffs and exerted tracheal pressures. Crit Care Med 2013;41(2):518-526.

7. Dullenkopf A, Schmitz A, Frei M, Gerber AC, Weiss M. Air leakage around endotracheal tube cuffs. Eur J Anesthesiol 2004;21(6):448453.

8. Dullenkopf A, Gerber A, Weiss M. Fluid leakage past tracheal tube cuffs: evaluation of the new Microcuff endotracheal tube. Intensive Care Med 2003;29(10):1849-1853.

9. Zanella A, Scaravilli V, Isgrò S, Milan M, Cressoni M, Patroniti N, et al. Fluid leakage across tracheal tube cuff, effect of different cuff material, shape, and positive expiratory pressure: a bench-top study. Intensive Care Med 2011;37(2):343-347.

10. Kolobow T, Cressoni M, Epp M, Corti I, Cadringher P, Zanella A. Comparison of a novel Lycra endotracheal tube cuff to standard polyvinyl chloride cuff and polyurethane cuff for fluid leak prevention. Respir Care 2011;56(8):1095-1099.

11. Mehta S. Safe lateral wall cuff pressure to prevent aspiration. Ann R Coll Surg Engl 1984;66(6):426-427.

12. American Thoracic Society, Infectious Diseases Society of America. Guidelines for the management of adults with hospital-acquired, ventilator-associated, and healthcare-associated pneumonia. Am J Respir Crit Care Med 2005;171(4):388-416.

13. Seegobin RD, van Hasselt GL. Endotracheal cuff pressure and tracheal mucosal blood flow: endoscopic study of effects of four large volume cuffs. Br Med J 1984;288(6422):965-968.

14. Nordin U. The trachea and cuff-induced tracheal injury: an experimental study on causative factors and prevention. Acta oto-laryngol Suppl 345:1-71, 1977.

15. Mujica-Lopez KI, Pearce MA, Narron KA, Perez J, Rubin BK. In vitro evaluation of endotracheal tubes with intrinsic suction. Chest 2010;138(4):863-869.

16. Williamson JP, McLaughlin RA, Noffsinger WJ, James AL, Baker VA, Curatolo A, et al. Elastic properties of the central airways in obstructive lung diseases measured using anatomical optical coherence tomography. Am J Respir Crit Care Med 2011;183(5):612-619.

17. Baier H, Zarzecki S, Wanner A. Influence of lung inflation on the cross-sectional area of central airways in normals and in patients with lung disease. Respiration 1981;41(3):145-154.
18. Walenga RL, Longest PW, Sundaresan G. Creation of an in vitro biomechanical model of the trachea using rapid prototyping. J Biomech 2014;47(8):1861-1868.

19. Xi J, Longest PW. Transport and deposition of micro-aerosols in realistic and simplified models of the oral airway. Ann Biomed Eng 2007;35(4):560-581.

20. Cheng KH, Cheng YS, Yeh HC, Swift DL. Measurements of airway dimensions and calculation of mass transfer characteristics of the human oral passage. J Biomech Eng 1997;119(4):476-482.

21. Shah S, Fung K, Brim S, Rubin BK. An in vitro evaluation of the effectiveness of endotracheal suction catheters. Chest 2005;128(5): 3699-3704.

22. Young PJ, Pakeerathan S, Blunt MC, Subramanya S. A low-volume, low-pressure tracheal tube cuff reduces pulmonary aspiration. Crit Care Med 2006;34(3):632-639.

23. Young PJ, Rollinson M, Downward G, Henderson S. Leakage of fluid past the tracheal tube cuff in a benchtop model. Br J Anaesth 1997;78(5):557-562.

24. Rello J, Soñora R, Jubert P, Artigas A, Rué M, Vallés J. Pneumonia in intubated patients: role of respiratory airway care. Am J Respir Crit Care Med 1996;154(1):111-115.

25. Blunt MC, Young PJ, Patil A, Haddock A. Gel lubrication of the tracheal tube cuff reduces pulmonary aspiration. Anesthesiology 2001;95(2):377-381.

26. Guyton DC, Barlow MR, Besselievre TR. Influence of airway pressure on minimum occlusive endotracheal tube cuff pressure. Crit Care Med 1997;25(1):91-94.

27. Harvey RC, Miller P, Lee JA, Bowton DL, MacGregor DA. Potential mucosal injury related to continuous aspiration of subglottic secretion device. Anesthesiology 2007;107(4):666-669.

28. Berra L, De Marchi L, Panigada M, Yu ZX, Baccarelli A, Kolobow T. Evaluation of continuous aspiration of subglottic secretion in an in vivo study. Crit Care Med 2004;32(10):2071-2078.

29. Nseir S, Brisson H, Marquette CH, Chaud P, Di Pompeo C, Diarra $\mathrm{M}$, et al. Variations in endotracheal cuff pressure in intubated critically ill patients: prevalence and risk factors. Eur J Anesthesiol 2009; 26(3):229-234.

30. Nseir S, Zerimech F, Fournier C, Lubret R, Ramon P, Durocher A, Balduyck M. Continuous control of tracheal cuff pressure and microaspiration of gastric contents in critically ill patients. Am J Respir Crit Care Med 2011;184(9):1041-1047.

This article is approved for Continuing Respiratory Care Education credit. For information and to obtain your CRCE

(free to AARC members) visit www.rcjournal.com

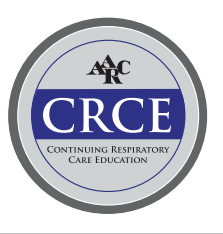

